\title{
Analysis of the core oligosaccharide of Aeromonas hydrophila (Chemotype III) lipopolysaccharide using fast atom bombardment, electrospray and low energy tandem mass spectrometry
}

\author{
Joseph Banoub ${ }^{1,2^{*}}$, Emmanuel Gentil ${ }^{1,2}$, and Derek H. Shaw ${ }^{1}$ \\ 1. Department of Fisheries \& Oceans, Northwest Atlantic Fisheries Center, Science \\ Branch, Toxicology Section P.O. Box 5667, St John's Newfoundland, A1C 5X1, \\ Canada, 2. Department of Biochemistry, Memorial University of Newfoundland, \\ St. John's, Newfoundland, A1B 3X9, Canada
}

\begin{abstract}
Fast-atom bombardment mass spectrometry (FAB-MS) was employed for the structural analysis of the core oligosaccharide of Aeromonas hydrophila (Chemotype III) lipopolysaccharide. Positive ion FAB-MS of the underivatized core oligosaccharide gave the protonated molecular ion, confirming the correct composition in terms of hexoses, heptoses and Kdo which was present as a bicyclic furanosidic lactone. Negative ion FAB-MS gave the deprotonated molecular ion and fragment ions which were derived from more than two cleavage events with charge retention at the reducing and non-reducing terminals. Positive ion FAB-MS of the permethylated core oligosaccharide afforded fragment ions consistent with the defined sequence and branching patterns of the sugar constituents. The electrospray mass spectrum (ESMS) in the positive ion mode of the underivatized core oligosaccharide afforded the protonated molecular ion in the singly and doubly charged forms. Low energy collision-activated dissociation tandem mass spectrometry (CAD MS/MS) analysis of the protonated molecular ion $[\mathrm{M}+2 \mathrm{H}]^{+2}$ provided additional structural data. ESMS of the permethylated and $\mathrm{N}$-acetylated permethylated core oligosaccharides provided useful structural indices and afforded a characteristic pattern for fragmentions resulting from the opening of the methylated bicyclic Kdo furanosidic 1,7lactone, which was similar to that obtained in the corresponding FAB-MS.
\end{abstract}

\section{Introduction}

Aeromonas hydrophila is a Gram-negative bacterium usually associated with outbreaks of disease in freshwater fish, particularly salmonids. More recently, it has been implicated in serious cases of human infection, which occasionally have resulted in death $[1,2]$. Studies conducted on the serological identity of members of the Aeromonas hydrophila group indicated an extraordinary degree of heterogeneity [3]. 
Interest in the structure and immunological properties of the cell-surface polysaccharide of the different chemotypes of this Gram-negative bacterium has increased due to the fact that little is known about the biochemical basis of the pathogenicity of these species [4-6].

In the initial elucidation of the core oligosaccharide structure of Aeromonas hydrophila (Chemotype III), we presented an incomplete structure. This was due to the fact that, both in our original studies [4] and in the original chemotaxonomic classification of this lipopolysaccharide (LPS) core [7], we could not determine the presence of the $\alpha$-D-Glc $p \mathrm{~N}-(1 \rightarrow 7)-\mathrm{L}-\alpha-\mathrm{D}-\mathrm{Hep} p$ disaccharide containing the D-glucosamine residue with a $\mathrm{C}-2$ free amino group. The glycosidic linkage of this disaccharide was extremely resistant to the hydrolysis conditions normally used during sugar analysis and, therefore, eluded detection by conventional methods. Also, we were unable to detect 3-deoxy-D-manno-2-octulosonic acid (Kdo) which was considered a ubiquitous constituent of the inner core region of the lipopolysaccharide of the majority of Gram-negative bacteria. However, at the time of our initial investigation it was commonly believed that Kdo was absent from the lipopolysaccharides of the Vibrionaceae family and its absence, as established by the thiobarbiturate-based colorimetric assay, was used as a taxonomical characteristic for classification [8].

Subsequently, we have demonstrated that Kdo is present in all of the LPS belonging to the family ${ }^{9}$, a result in direct contrast to the generally accepted view of the absence of this compound. The precise molecular structure of the core oligosaccharide from the cell surface has been revisited using state-of-the-art mass spectrometric techniques. It is well documented that mass spectrometry using surface ionization modes such as FAB is a powerful technique for the structural investigation of complex carbohydrates including those that contain labile and polar groups [10]. Electrospray ionization (ES) is well established as a robust LC-MS technique that allows rapid, accurate and sensitive analysis of a wide range of analytes from low molecular weight polar compounds (less than $200 \mathrm{Da}$ ) to biopolymers larger than $100 \mathrm{kDa}$ [11].

We now report on the application of FAB-MS and ESMS in the analysis of the structure of the core oligosaccharide of Aeromonas hydrophila (Chemotype III). The results of positive ion FAB-MS and ESMS of derivatized permethylated and $\mathrm{N}$-acetylated permethylated products can be used to confirm the results obtained by negative and positive FAB-MS and positive ESMS of the underivatized oligosaccharide. We also report on the ring opening of the reducing Kdo which was found to be present in a bicyclic furanosidic lactone form, during the permethylation of the core oligosaccharide.

\section{Results and discussion}

In the recent course of structural investigation of the precise molecular structure of the lipopolysaccharide of the Gram negative bacterium of Aeromonas hydrophila (Chemotype III), we isolated the disaccharide 7-O-(2-amino-2-deoxy- $\alpha$-D-glucopyranosyl)-Lglycero-D-manno-heptose 1 , following hydrolysis of the respective core oligosaccharides with $2 \mathrm{M}$ hydrochloric acid for $1 \mathrm{~h}$ at $100^{\circ} \mathrm{C}$. The same aminoglycosylheptose 1 had been previously identified in the core region of the LPS of Escherichia coli [12], Bordetella pertussis [13] and Aeromonas hydrophila (Chemotype I and II) [5,6,14]. Deamination of the native core oligosaccharide $[5,6]$, followed by methylation analysis, established that the monosubstituted aminoglycosylheptose 1 was substituted by an $\alpha$-D-glucopyranosyl residue through the C-4 position of its heptose portion. When the core oligosaccharide of Aeromonas hydrophila (Chemotype III) was methylated by the Hakomori method, followed by hydrolysis with $2 \mathrm{M}$ trifluoroacetic acid, reduction, acetylation and identification by gas- 


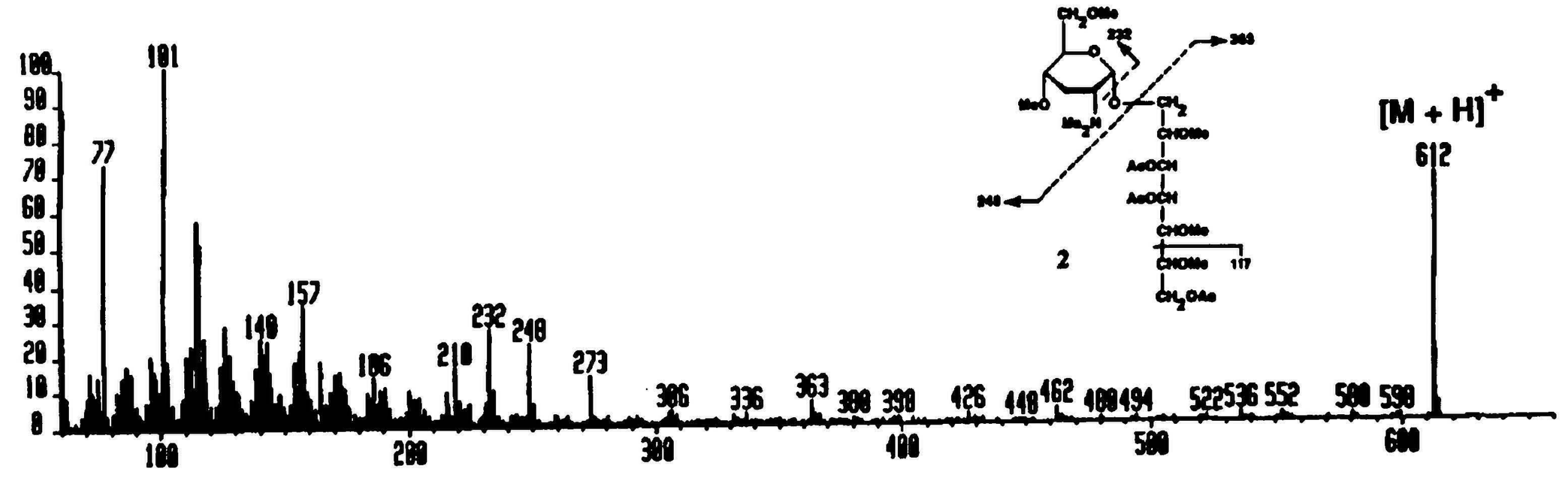

Figure 1. $\mathrm{CI}-\left(\mathrm{NH}_{3}\right)$-MS of 1,4,5-tri- $O$-acetyl-7- $O$-[2-deoxy-2-(dimethylamine)-3,4,6-tri- $O$-methyl- $\alpha$-Dglucopyranosyl]-2,3,6-tri-O-methyl-L-glycero-D-manno-heptitol 2.

Figure 2. Positive ion FAB-MS of the native core oligosaccharide of Aeromonas hydrophila (Chemotype III) (matrix : (a) glycerol / thioglycerol, (b) dithioerythritol / dithiothreitol).

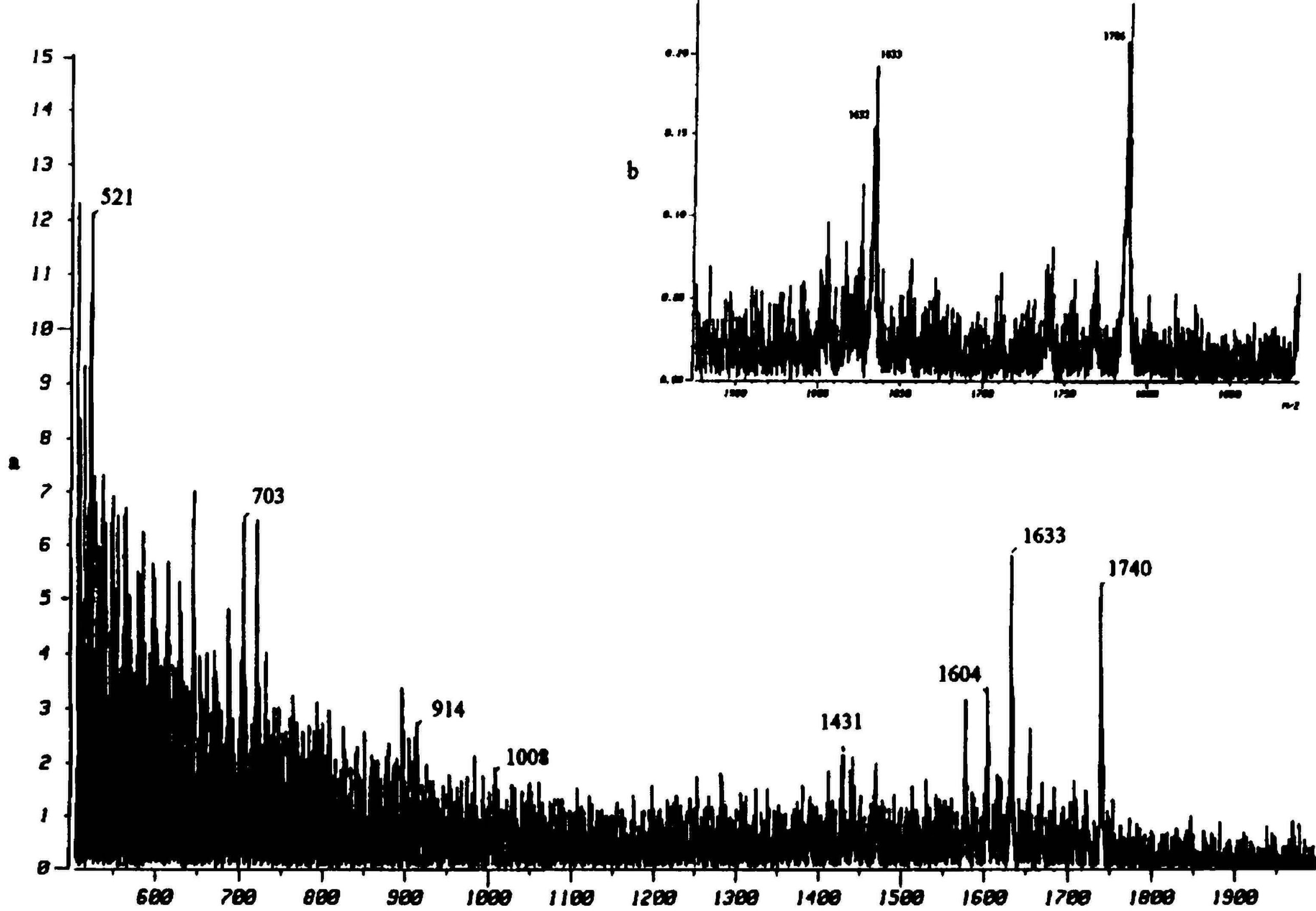


liquid chromatography, we noticed a slow-moving component, whose identity was established by chemical ionization-mass spectrometry as 1,4,5-tri- $O$-acetyl-7- $O$-[2-deoxy-2(dimethylamine)-3,4,6-tri- $O$-methyl- $\alpha$-D-glucopyranosyl]2,3,6-tri- $O$-methyl-L-glycero-D manno-heptitol 2. This had not been detected in the previous investigation. The CI-( $\left.\mathrm{NH}_{3}\right)-$ MS showed, as major peaks, the protonated molecular ion $[\mathrm{M}+\mathrm{H}]^{+}$at $\mathrm{m} / \mathrm{z} 612$, together with the fragment ions $\mathrm{A}^{+}$and $\mathrm{Ald}^{+}$at $\mathrm{m} / \mathrm{z} 232$ and 363, which are diagnostic for the glycosyl residue and alditol portion of this glycosylalditol derivative 2 (see Figure 1), respectively. The presence of the glycosylalditol derivative 2 in this analysis could be attributed to the fact that this core oligosaccharide contained the trisaccharide 7-O-[2amino-2-deoxy- $\alpha$-D-glucopyranosyl]-4-O-[ $\alpha$-D-glucopyranosyl]-L-glycero-D-mannoheptapyranose which escaped detection in the previous investigation.

Identification of 3-deoxy-D-manno-2-octulosonic acid (Kdo) was achieved by GCEI-MS and it was found that this core oligosaccharide contained only one residue of Kdo which connected the native oligosaccharide to the Lipid A [9]. We have suggested that the reducing Kdo was prone to form a lactone [15], and it was established that the single Kdo residue of this family of bacteria, which glycosidically attaches the core oligosaccharide to the non-reducing glucosamine unit of Lipid A, was in the furanose form [16,17] and linked through C-6.

On the basis of these new findings, combined with 2D NMR studies (COSY, DEPT and HETCOR), this core oligosaccharide was found to be composed of residues of Dgalactose, D-glucose, L-glycero-D-manno-heptose, 3-acetamido-3,6-dideoxy-L-glucose, 2amino-2-deoxy-D-glucose and 3-deoxy-D-manno-2-octulosonic acid, in the approximate molar ratio of 1:2:3:1:1:1. The revised chemical structure of the core oligosaccharide of Aeromonas hydrophila, (Chemotype III), is as follows:

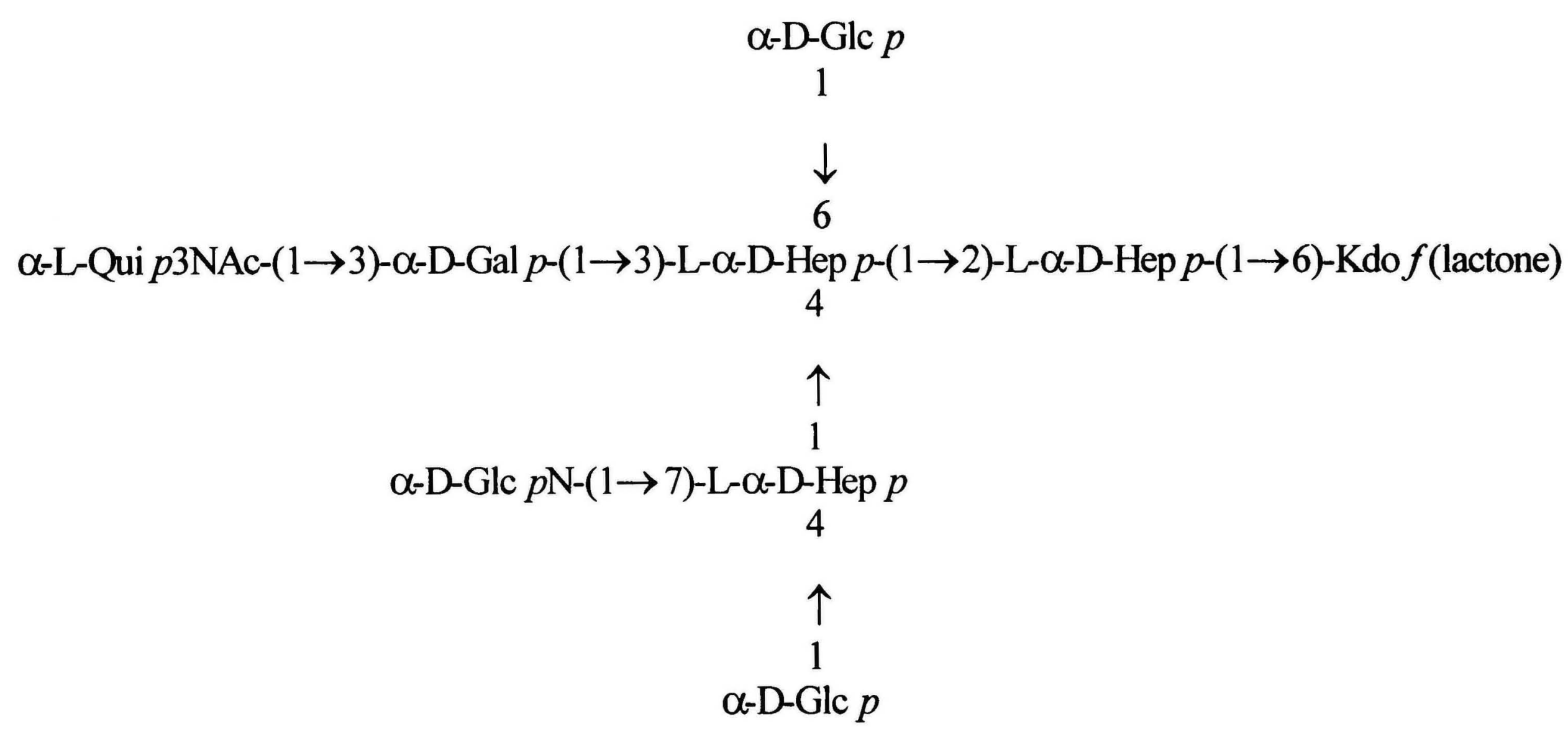

Note that both the revised structure proposed in this rationale and the one presented in our previous studies would afford the same Smith degraded product, namely:

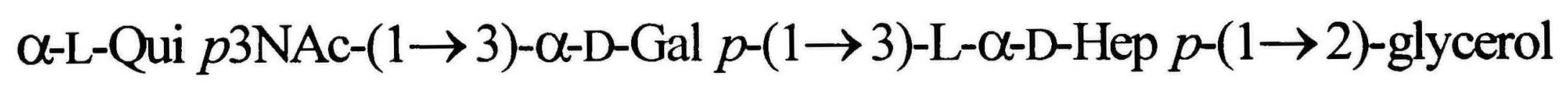

Using positive ion $\mathrm{FAB}-\mathrm{MS}$, the native core oligosaccharide was determined to be $\mathrm{C}_{61} \mathrm{H}_{102} \mathrm{~N}_{2} \mathrm{O}_{48}$ with a molecular weight of 1631 . Using two different matrix mixtures composed of glycerol/thioglycerol (1:3) and dithioerythritol/dithiothreitol (1:5) we noticed a cluster of ions of which the most abundant were the protonated molecular ion $[\mathrm{M}+\mathrm{H}]^{+}$at $\mathrm{m} / \mathrm{z} 1632$ and its ${ }^{13} \mathrm{C}$-isotope peak at $\mathrm{m} / \mathrm{z} 1633$. The ion at 1632 is consistent with the

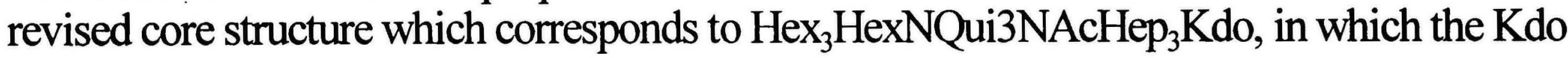


furanose exists as 1,7-lactone. The protonated molecular adducts [M+H + thioglycerol $]^{+}$and $[\mathrm{M}+\mathrm{H}+\text { dithioerythritol }]^{+}$and their ${ }^{13} \mathrm{C}$-isotope peaks were also observed at $\mathrm{m} / \mathrm{z} 1740,1741$, 1786 and 1787 respectively, as shown in Figure 2. It should be noted that except for molecular mass determination, no useful structural sequence information could be obtained from the FAB-MS using these two different matrices.

In contrast, the negative ion FAB-MS of the native core oligosaccharide, using a mixture of glycerol/thioglycerol (1:3) as matrix, showed the deprotonated molecular ion [M$\mathrm{H}]^{-}$and its ${ }^{13} \mathrm{C}$-isotope ion at $\mathrm{m} / \mathrm{z} 1630$ and 1631 respectively. Other diagnostic fragment ions were also observed which permitted the confirmation of structural sequences of this branched core oligosaccharide (Figure 3).

The fragmentation routes of this negative ion FAB-MS, shown in Figure 4, have been rationalized using the scheme for systematic nomenclature for carbohydrate fragmentation in FAB-MS proposed by Domon and Costello $[18,19]$ to describe putative fragmentation processes. Briefly, fragments with charge retention on the non-reducing terminus are designated $\mathrm{A}, \mathrm{B}$ and $\mathrm{C}$, while the reducing terminal fragments are similarly designated $\mathrm{X}, \mathrm{Y}$ and $\mathrm{Z}$. Fragments $\mathrm{A}$ and $\mathrm{X}$ contain superscript numbers designating the two bonds involved in ring cleavage which would account for the observed masses of these fragment series. Subscript numbers identify the residue number, while accompanying $\alpha, \beta$, etc., indicate the branch involved where $\alpha$ applies to the branch of highest mass. We have observed a series of "Y-type" fragment ions in which charge retention occurred on the reducing terminal end. Thus, the fragment ion $[\mathrm{M}-\mathrm{H}-162]^{-}$at $\mathrm{m} / \mathrm{z} 1468$ was attributed to the loss of one glucose residue from the deprotonated molecular ion and was assigned as $\mathrm{Y}_{3 \alpha, 4 \alpha}$ [M-H-Glc]. The fragment ion [M-H-349] at $\mathrm{m} / \mathrm{z} 1281$ was assigned as $\mathrm{Y}_{3 \beta}[\mathrm{M}-\mathrm{H}-$ Qui3NAc $(1 \rightarrow 3)$ Gall]. Also, we observed the fragment ion [M-H-703] at $\mathrm{m} / \mathrm{z} 927$ which was formed by a double cleavage and attributed to $\mathrm{Y}_{3 \alpha+4 \beta}[\mathrm{M}-\mathrm{H}-\mathrm{Qui} 3 \mathrm{NAc}-\mathrm{Glc}-\mathrm{GlcN}(1 \rightarrow 7) \mathrm{Hep}]-$ .This latter ion was assigned to the following deprotonated pentasaccharide:

$$
\begin{gathered}
\text { Glc } \\
1 \\
\downarrow \\
6 \\
{[\operatorname{Gal}(1 \rightarrow 3) \operatorname{Hep}(1 \rightarrow 2) \mathrm{Hep}(1 \rightarrow 6) \mathrm{Kdo} f(1,7 \text {-lactone })]^{-}} \\
\mathrm{Y}_{3 \alpha+4 \beta} \quad \mathrm{m} / \mathrm{z} 927
\end{gathered}
$$

We could also observe the simple $\mathrm{Y}_{2}$ fragment ion $[\mathrm{Hep}(1 \rightarrow 6) \mathrm{Kdo} f(1,7 \text {-lactone })]^{-}$ at $\mathrm{m} / \mathrm{z}$ 411. It should be noted that charge retention was not restricted to one end of the molecule as demonstrated by the presence of "A-ring type cleavage" products in which more than one bond, often accompanied by molecular rearrangements $[18,19]$, appears to split the same molecule as exemplified by the major fragment ions at $\mathrm{m} / \mathrm{z} 766$ and 426 tentatively assigned, respectively, as:

$$
[\mathrm{GlcN}(1 \rightarrow 7) \mathrm{Hep}(1 \rightarrow 3) \mathrm{Hep}(1 \rightarrow \mathrm{OCH}=\mathrm{CHOH})-\mathrm{H}]^{-}
$$

$$
\begin{aligned}
& \stackrel{4}{\uparrow} \\
& 1 \\
& \text { Glc } \\
& \mathrm{Y}_{3 \alpha^{\alpha}+3 \beta}+{ }^{1,3} \mathrm{~A}_{4} \quad \mathrm{~m} / \mathrm{z} 766
\end{aligned}
$$


and

$$
\begin{gathered}
{[\mathrm{GlcN}(1 \rightarrow 7) \mathrm{Hep}(1 \rightarrow \mathrm{OCH}=\mathrm{CH}-\mathrm{CHOH})]^{-}} \\
\mathrm{Y}_{4 \alpha^{\circ}}+{ }^{0,3} \mathrm{~A}_{3}+\mathrm{B}_{3} \quad \mathrm{~m} / \mathrm{z} 426
\end{gathered}
$$

The data obtained from the various fragment ions obtained by negative ion FAB-MS corroborates the majority of sequences proposed for the revised structure and confirms, once more, the presence of the Kdo furanose residue reducing end group which is present as a 1,7-lactone.

The positive ion FAB-MS of the permethylated core oligosaccharide prepared by Hakomori methylation using m-nitrobenzyl alcohol as a matrix is shown in Figure 5. The protonated molecular ion $[\mathrm{M}+\mathrm{H}]^{+}$at $\mathrm{m} / \mathrm{z} 2066\left[\mathrm{C}_{92} \mathrm{H}_{164} \mathrm{~N}_{2} \mathrm{O}_{48}\right.$, M.Wt. $\left.2065 \mathrm{Da}\right]$ shows an increase of $434 \mathrm{Da}$ resulting from the incorporation of 31 methyl groups, which is consistent with the core oligosaccharide structure $\mathrm{Hex}_{3} \mathrm{HexNQui3NAcHep} \mathrm{Kdo}_{3}$ (lactone) in which all hydroxyl, amine and amide groups are fully methylated. A major diagnostic fragment-ion resulting from multiple cleavages was observed at $\mathrm{m} / \mathrm{z} 884$. This fragment-ion was assigned to a matrix adduct of the protonated methylated trisaccharide $\mathrm{Y}_{3 \alpha+3 \alpha+3 \beta}$ ion namely the $[\mathrm{Hep}(1 \rightarrow 2) \mathrm{Hep}(1 \rightarrow 6) \mathrm{Kdof} \text { (lactone) }+\mathrm{H}+153]^{+}$ion. We also noticed a series of diagnostic "B-fragment ions" resulting from charge retention at the non-reducing end at $\mathrm{m} / \mathrm{z} 219,230,232$, and 434 which were assigned respectively to the following permethylated oxonium ions: [Glc] $]^{+},[\mathrm{Qui} 3 \mathrm{NMeAc}]^{+},\left[\mathrm{GlcNMe}_{2}\right]^{+}$and the disaccharide [Qui3NMeAc- $(1 \rightarrow 3)-G a l]^{+}$. Another important B diagnostic ion was observed at m/z 1153 and was assigned to the pentasaccharide ion having the following structure:

$$
\begin{gathered}
{\left[\mathrm{GlcN}(\mathrm{Me})_{2}(1 \rightarrow 7) \mathrm{Hep}(1 \rightarrow 3) \mathrm{Hep}(1 \rightarrow 2) \mathrm{Hep}^{+}\right.} \\
\uparrow \\
1 \\
\text { Glc } \\
\mathrm{Y}_{3 \alpha^{+}+3 \beta}+\mathrm{B}_{4} \quad \mathrm{~m} / \mathrm{z} 1153
\end{gathered}
$$

which resulted from the loss of the bicyclic Kdo furanosidic 1,7-lactone.The fragment ion at $\mathrm{m} / \mathrm{z} 466$ was assigned as the expected monohydroxylated disaccharide oxonium ion:

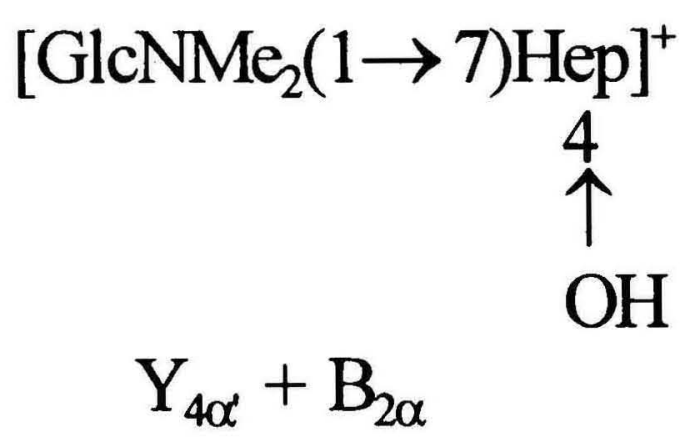

In addition we also observed a major fragment ion at $\mathrm{m} / \mathrm{z} 480$ which was assigned to the fully methylated disaccharide oxonium ion:

$$
\begin{gathered}
{\left[\mathrm{GlcNMe}_{2}(1 \rightarrow 7) \mathrm{Hep}\right]^{+}} \\
\mathrm{Y}_{4 \alpha^{\prime}}+\mathrm{B}_{2 \alpha}
\end{gathered}
$$




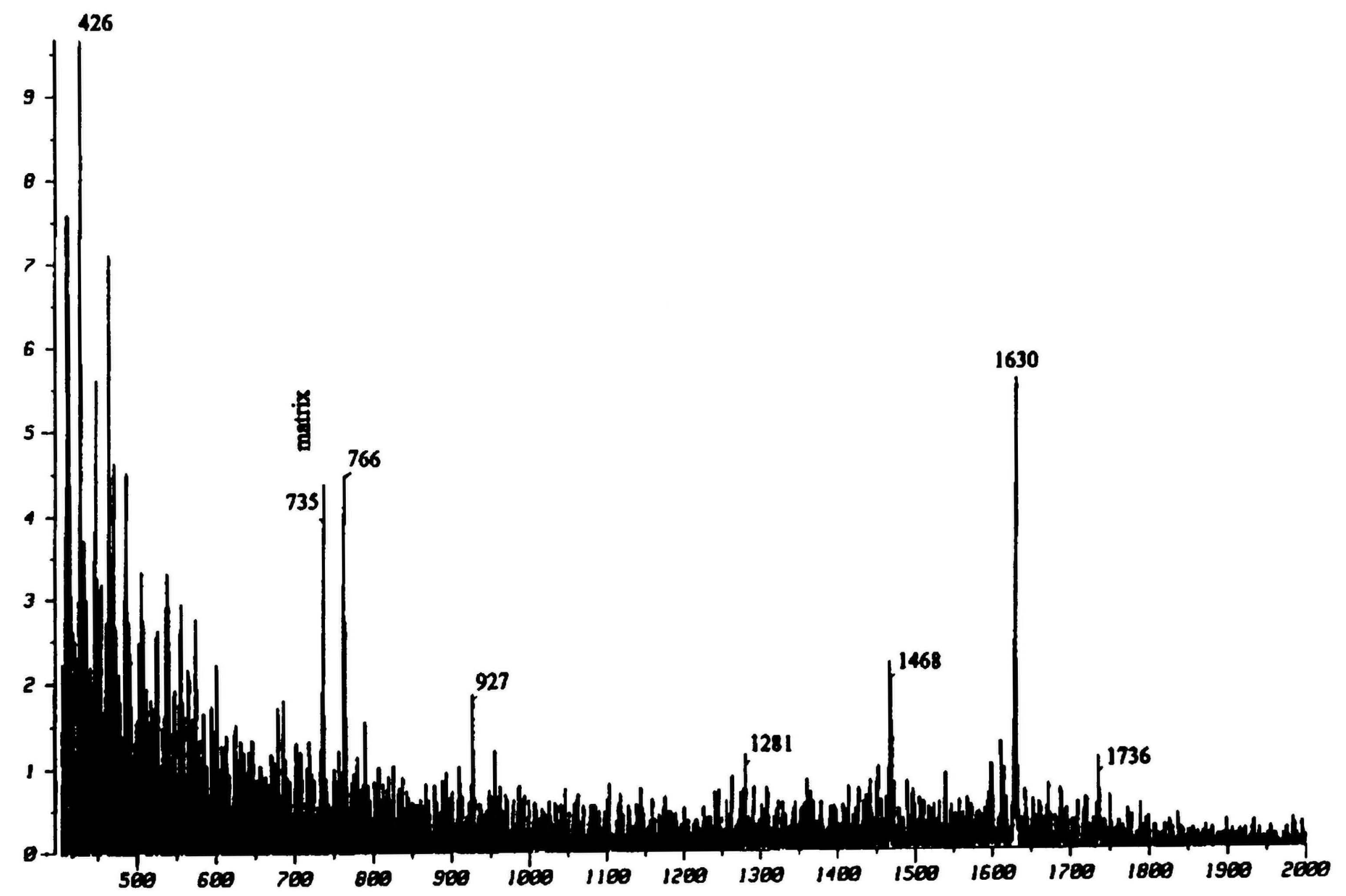

Figure 3. Negative ion FAB-MS of the native core oligosaccharide of Aeromonas hydrophila (Chemotype III).

Figure 4. Fragmentation routes of the core oligosaccharide of Aeromonas hydrophila (Chemotype III) obtained in the negative ion FAB-MS.

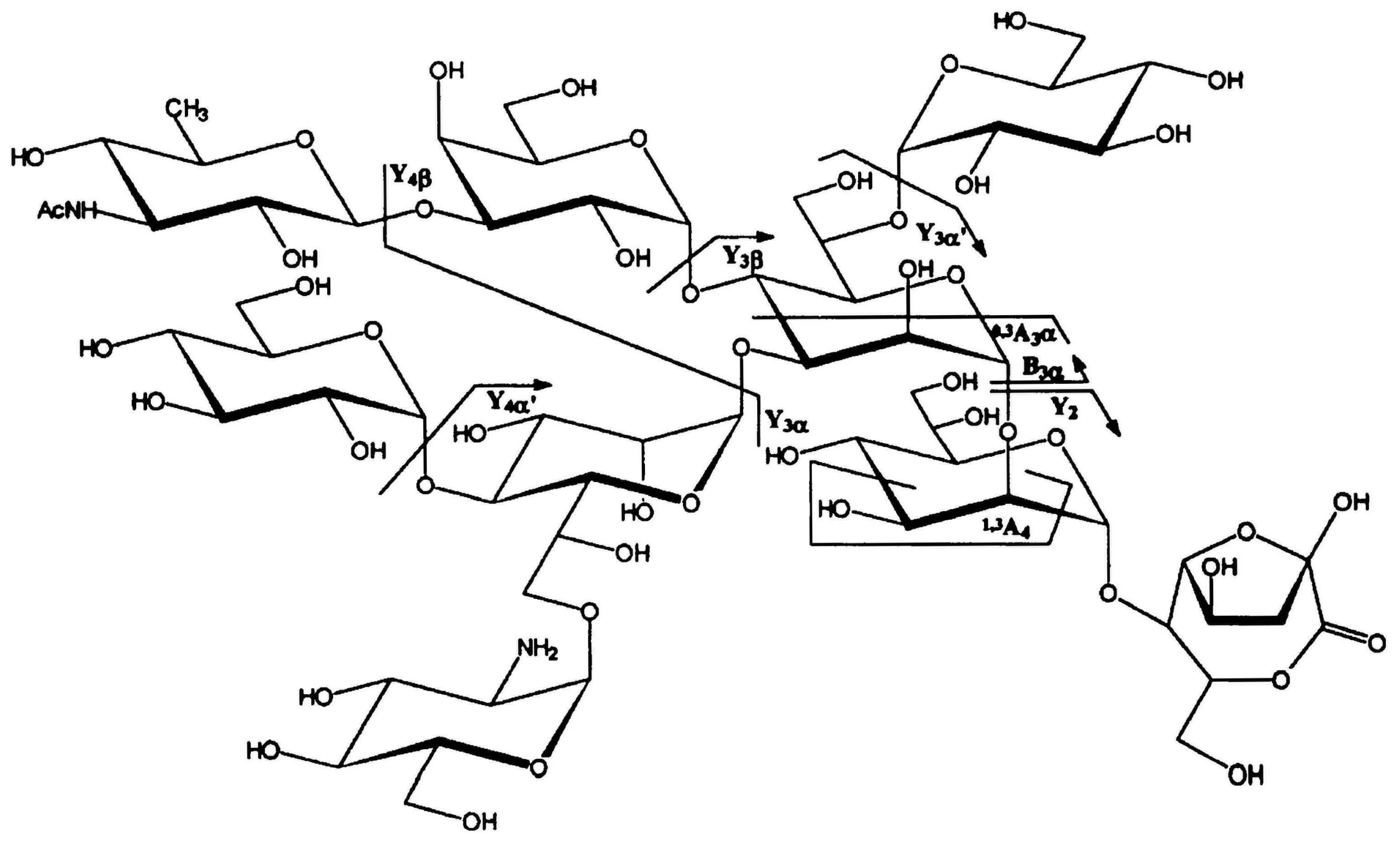


The formation of this fully methylated oxonium ion may be explained by an intermolecular reaction in the gaseous phase [20], between another methylated compound and the original monohydroxylated disaccharide oxonium ion at $\mathrm{m} / \mathrm{z} 466$. The tentative structures of these fragment ions are illustrated in Figure 6.

It is imperative to mention that in the FAB-MS of the permethylated core oligosaccharide we did not observe the characteristic fragment ions resulting from the loss of "46" and "116" $\mathrm{Da}$, a diagnostic pattern that has been observed only for core oligosaccharides that contain "normal" reducing pyranose Kdo residue [21].

We have also observed a cluster of higher masses resulting from increments of 14 $\mathrm{Da}$ and corresponding to a series of protonated molecular ions. Those were tentatively assigned as resulting from the lactone ring opening of the bicyclic furanosidic Kdo 1,7lactone. It has already been suggested by Dell and coworkers [21] that C-methylation of Kdo residue was possible and we propose that the bicyclic furanosidic Kdo 1,7-lactone may undergo a similar process. This may occur either as a result of overmethylation or, possibly, by an intrinsically proper reaction resulting from the 1,7-lactone opening by the dimsyl anions as shown in Figure 6. The latter would result in the protonated molecular ions $[\mathrm{M}+\mathrm{H}+\mathrm{Me}]^{+}\left(\mathrm{C}_{93} \mathrm{H}_{167} \mathrm{~N}_{2} \mathrm{O}_{48}\right),[\mathrm{M}+\mathrm{H}+2 \mathrm{Me}]^{+}\left(\mathrm{C}_{94} \mathrm{H}_{169} \mathrm{~N}_{2} \mathrm{O}_{48}\right),[\mathrm{M}+\mathrm{H}+3 \mathrm{Me}]^{+}\left(\mathrm{C}_{95} \mathrm{H}_{171} \mathrm{~N}_{2} \mathrm{O}_{48}\right)$ and $[\mathrm{M}+\mathrm{H}+4 \mathrm{Me}]^{+}\left(\mathrm{C}_{96} \mathrm{H}_{173} \mathrm{~N}_{2} \mathrm{O}_{48}\right)$ at $\mathrm{m} / \mathrm{z} 2080,2094,2108$ and 2122 respectively, resulting from the incorporation of 1 to 4 extra methyl groups. These protonated molecular ions were tentatively rationalized as resulting first from opening of the lactone by the dimsyl anion to form consecutively the methyl ester followed by elimination of $\mathrm{H}-8$ to afford the $[\mathrm{M}+\mathrm{H}+\mathrm{Me}]^{+}$ion. This process is followed by $\mathrm{C}$-methylation of $\mathrm{C}-8$ to form the $[\mathrm{M}+\mathrm{H}+2 \mathrm{Me}]^{+}$ion, then $\mathrm{C}-$ methylation of $\mathrm{C}-3$ to form the $[\mathrm{M}+\mathrm{H}+3 \mathrm{Me}]^{+}$ion and finally by another $\mathrm{C}$-methylation of $\mathrm{C}-3$ to form the $[\mathrm{M}+\mathrm{H}+4 \mathrm{Me}]^{+}$ion (Figure 6).

Electrospray MS in the positive ion mode afforded the spectrum shown in Figure 7. We could observe the singly charged protonated molecule $[\mathrm{M}+\mathrm{H}]^{+}$at $\mathrm{m} / \mathrm{z} 1632$ and the doubly charged diprotonated molecule $[\mathrm{M}+2 \mathrm{H}]^{+2}$ at $\mathrm{m} / \mathrm{z} 817$ reconfirming the molecular weight of this core oligosaccharide. Two singly charged fragment ions were also observed at $\mathrm{m} / \mathrm{z} 1470$ and 1283 which were assigned as [M+H-Glc] $]^{+}$and [M+H- Glc-Qui3NAc] ${ }^{+}$. It should be noted that the ESMS was, indeed, cleaner than the FAB-MS and contained less fragments, no major background ambiguities and no matrix ions. Low energy tandem mass spectrometric analysis was conducted to rationalize the fragmentation pattern obtained in the conventional ESMS. Product ion spectra (also called daughter ion scan) arising from fragmentation in the RF-only hexapole collision cell of the quadrupole-hexapole-quadrupole instrument $[22,23]$ was obtained. The $[\mathrm{M}+2 \mathrm{H}]^{+2}$ ion at $\mathrm{m} / \mathrm{z} 817$ was selected for the recording of the unimolecular mass-analyzed ion kinetic energy (MIKE) and collision activated dissociation MS/MS analyses. The CAD MS/MS of the $[\mathrm{M}+2 \mathrm{H}]^{+2}$ ion of the core oligosaccharide is presented in Figure 8 and suggests the formation of two major Y-product ions at $\mathrm{m} / \mathrm{z} 1444$ and 1283 assigned as [M+H-Qui3NAc] $]^{+}$and [M+H-Qui3NAc-Hex] ${ }^{+}$, respectively. These two Y-product ions were the result of fragmentation with charge retention at the reducing end. Please note that in the CAD MS/MS of the $[\mathrm{M}+2 \mathrm{H}]^{2+}$ precursor ion, we observed the formation of the exclusive diagnostic ion [M+H-Qui3NAc $]^{+}$ at $\mathrm{m} / \mathrm{z} 1444$ which was absent in the conventional ESMS. This low energy CAD MS/MS analysis provided additional confirmation of the structure of this core oligosaccharide.

The ESMS of the permethylated core oligosaccharide $\left(\mathrm{C}_{92} \mathrm{H}_{164} \mathrm{~N}_{2} \mathrm{O}_{48}\right.$, M.Wt. 2065 Da) afforded (Figure 9) the protonated molecular ion $[\mathrm{M}+\mathrm{H}]^{+}$at $\mathrm{m} / \mathrm{z} 2066$ and the characteristic series of higher molecular weight ions $[\mathrm{M}+\mathrm{H}+\mathrm{Me}]^{+}\left(\mathrm{C}_{93} \mathrm{H}_{167} \mathrm{~N}_{2} \mathrm{O}_{48}\right)$, $[\mathrm{M}+\mathrm{H}+2 \mathrm{Me}]^{+}\left(\mathrm{C}_{94} \mathrm{H}_{169} \mathrm{~N}_{2} \mathrm{O}_{48}\right),[\mathrm{M}+\mathrm{H}+3 \mathrm{Me}]^{+}\left(\mathrm{C}_{95} \mathrm{H}_{171} \mathrm{~N}_{2} \mathrm{O}_{48}\right)$ and $[\mathrm{M}+\mathrm{H}+4 \mathrm{Me}]^{+}\left(\mathrm{C}_{96} \mathrm{H}_{173} \mathrm{~N}_{2} \mathrm{O}_{48}\right)$ at $\mathrm{m} / \mathrm{z} \mathrm{2080}, 2094,2108$ and 2122, respectively, resulting from the opening of the 1,7lactone ring of $\mathrm{Kdo}$ and $\mathrm{C}-$ methylations as indicated previously. 


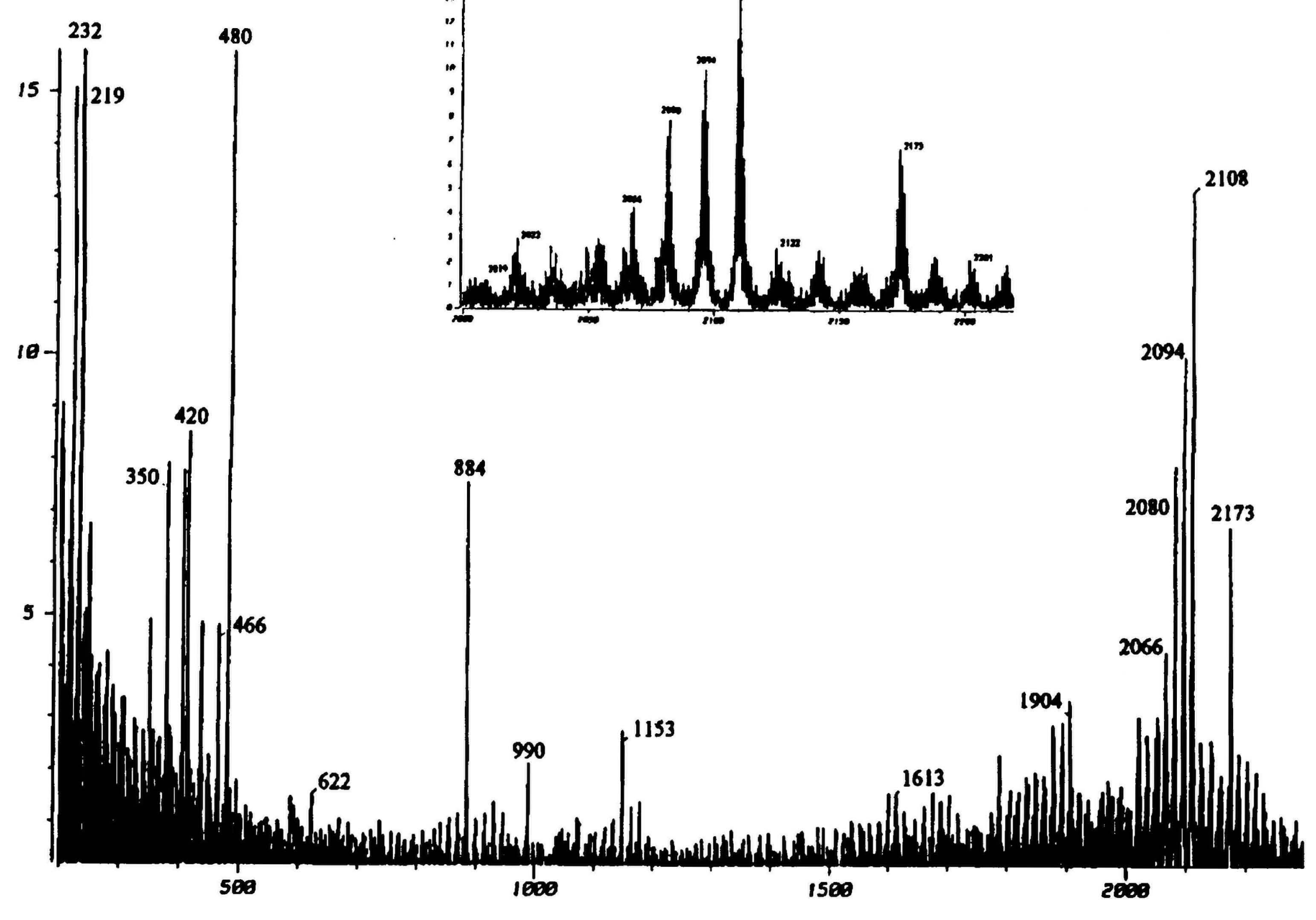

Figure 5. Positive ion FAB-MS of the permethylated core oligosaccharide of Aeromonas hydrophila (Chemotype III) (matrix : m-NBA).

Finally, the ESMS of the permethylated, $\mathrm{N}$-acetylated core oligosaccharide $\left(\mathrm{C}_{93} \mathrm{H}_{164} \mathrm{~N}_{2} \mathrm{O}_{49}\right.$, M.Wt. $\left.2093 \mathrm{Da}\right)$, in which the C-2 amino group of the GlcN $(1 \rightarrow 7) \mathrm{Hep}$ residue was previously acetylated, afforded (Figure 10) the protonated molecule $[\mathrm{M}+\mathrm{H}]^{+}$ at $\mathrm{m} / \mathrm{z}$ 2094, which corresponds to an increase of $420 \mathrm{Da}$ (i.e. 30 methyl groups) which is in agreement with the proposed structure. Again, we observed the higher masses corresponding to the $[\mathrm{M}+\mathrm{H}+\mathrm{Me}]^{+}\left(\mathrm{C}_{94} \mathrm{H}_{167} \mathrm{~N}_{2} \mathrm{O}_{49}\right), \quad[\mathrm{M}+\mathrm{H}+2 \mathrm{Me}]^{+} \quad\left(\mathrm{C}_{95} \mathrm{H}_{169} \mathrm{~N}_{2} \mathrm{O}_{49}\right)$, $[\mathrm{M}+\mathrm{H}+3 \mathrm{Me}]^{+}\left(\mathrm{C}_{96} \mathrm{H}_{171} \mathrm{~N}_{2} \mathrm{O}_{49}\right)$ and $[\mathrm{M}+\mathrm{H}+4 \mathrm{Me}]^{+}\left(\mathrm{C}_{97} \mathrm{H}_{173} \mathrm{~N}_{2} \mathrm{O}_{49}\right)$ at $\mathrm{m} / \mathrm{z} 2108,2122,2136$ and 2150 resulting from the opening of the 1,7-lactone ring of $\mathrm{Kdo}$ and $\mathrm{C}$-methylations as indicated previously.

\section{Experimental}

Core oligosaccharide was prepared from the LPS of the parent bacteria, and gasliquid chromatography of the partially methylated alditol acetates and the peracetylated methyl glycosides was performed, as previously described [4].

FAB analyses (positive and negative ion mode) were performed on a VG ZAB2SEQ mass spectrometer (VG Analytical Ltd, Manchester, U.K.) with a BeqQ design, mass range $15 \mathrm{kDa}$, ion energy $8 \mathrm{kV}$, fitted with a cesium ion gun delivering approximately 2 

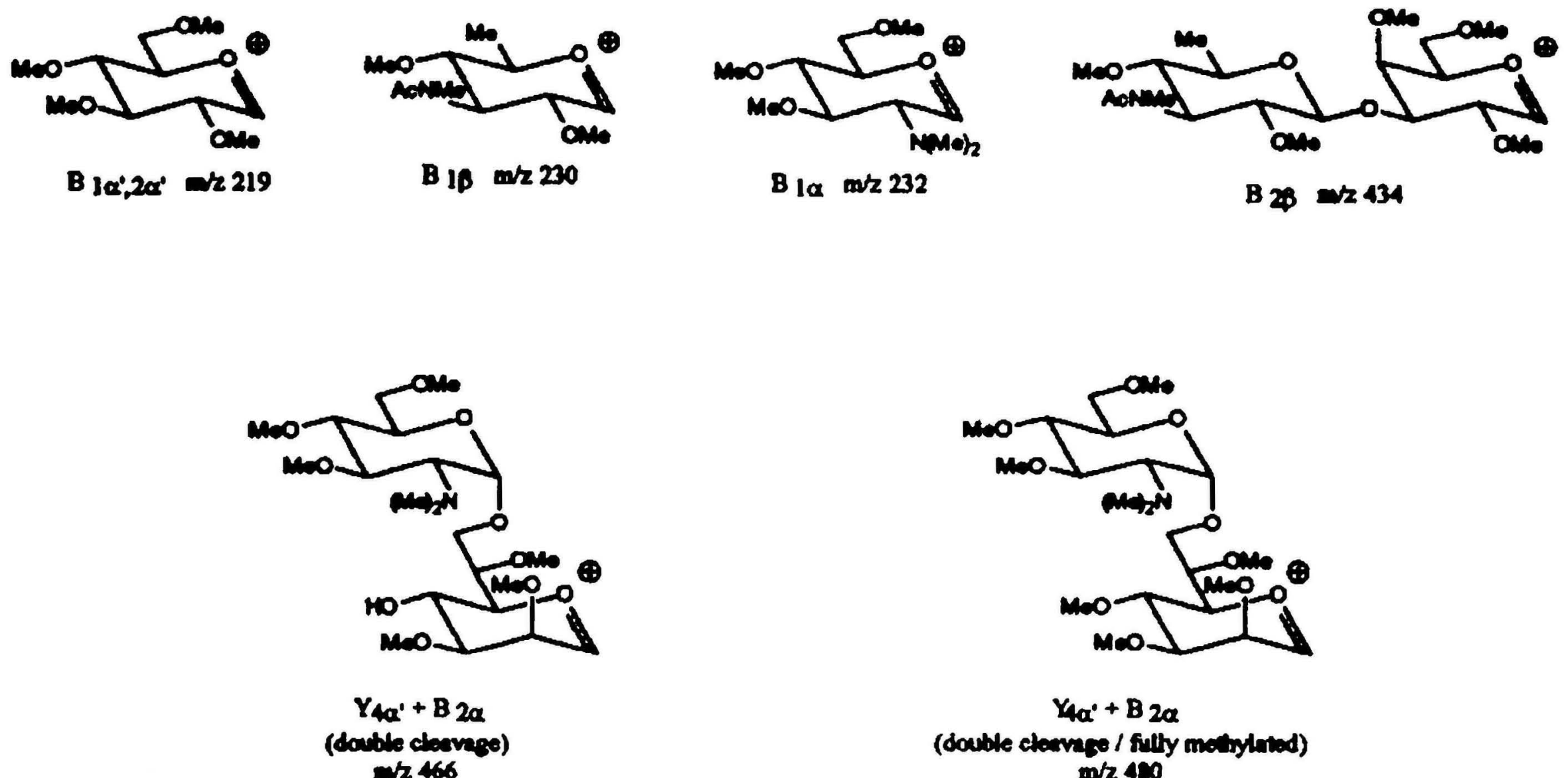

$4 a^{\circ}+B 2 a$

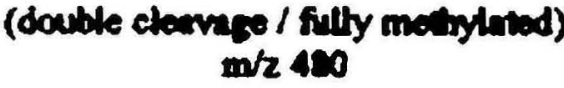

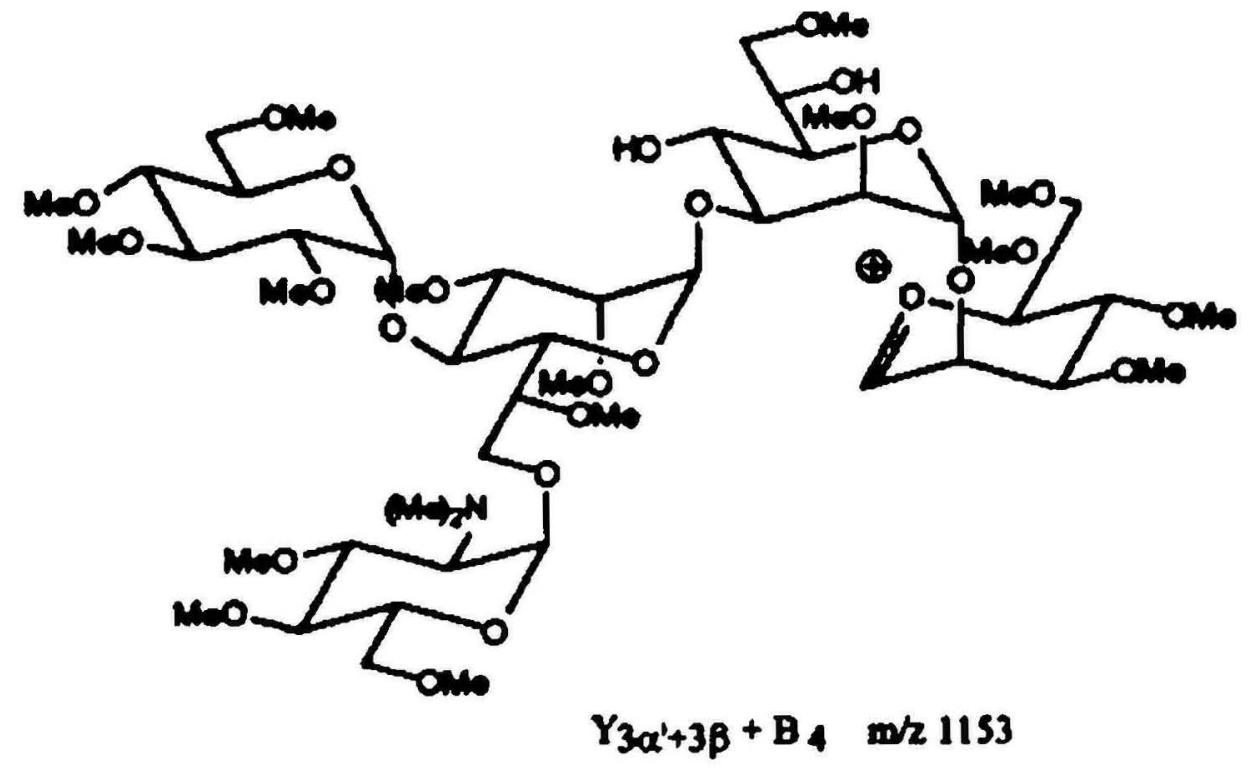

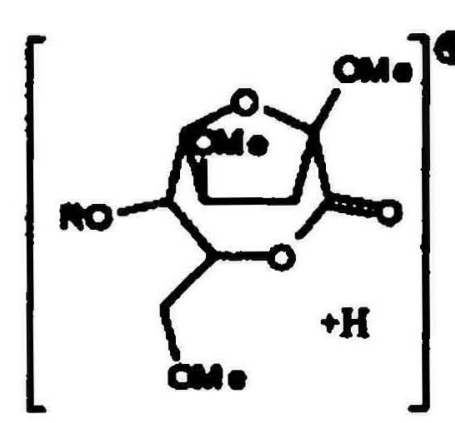

$\left[\mathbf{M}+\mathbf{H}^{+}\right.$ $\underset{n 22066}{\mathrm{CnH}_{100}}$

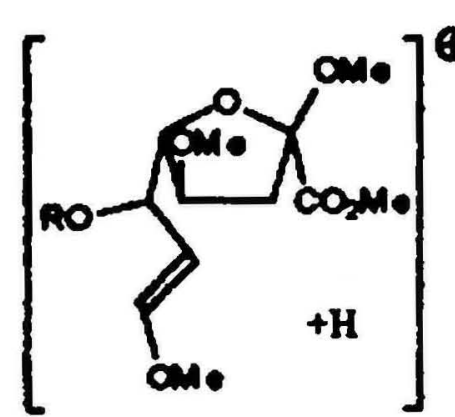

$\left[\mathrm{M}+\mathrm{H}+\mathrm{M} \mathrm{e}^{+}\right.$ $\mathrm{C}_{33} \mathrm{H}_{\mathrm{M}_{7} \mathrm{~N}_{2} \mathrm{O}}$ ar2 2020

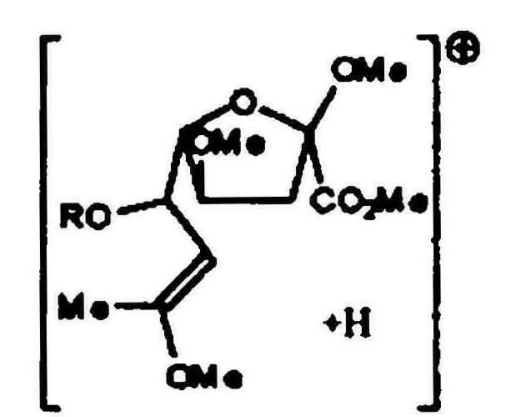

$[\mathrm{M}+\mathrm{H}+2 \mathrm{Me}]^{+}$ $\mathrm{C}_{\mathrm{m}} \mathrm{H}_{\mathrm{Hon}} \mathrm{N}_{2} \mathrm{O}_{4}$

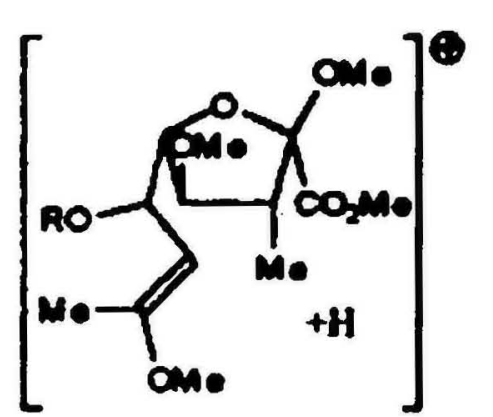

$\mathrm{M}+\mathrm{H}+3 \mathrm{Me}]^{+}$
$\mathrm{Cosh}_{1 \eta} \mathrm{N}_{2} \mathrm{O}_{-}$ $\mathrm{Cosh}_{17} \mathrm{H}_{2} \mathrm{O}_{2}$
2108

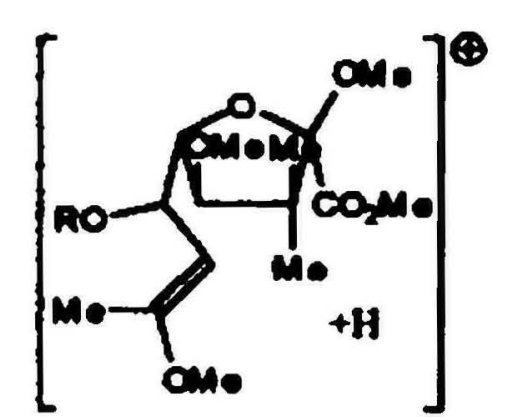

$[\mathrm{M}+\mathrm{H}+\mathbf{4} \mathrm{Me}]^{+}$ $\mathrm{C}_{3} \mathrm{H}_{13} \mathrm{~N}_{2} \mathrm{O}$

Figure 6. Chemical structure of the fragment-ions observed in positive ion FAB-MS of the permethylated core oligosaccharide of Aeromonas hydrophila (Chemotype III). 


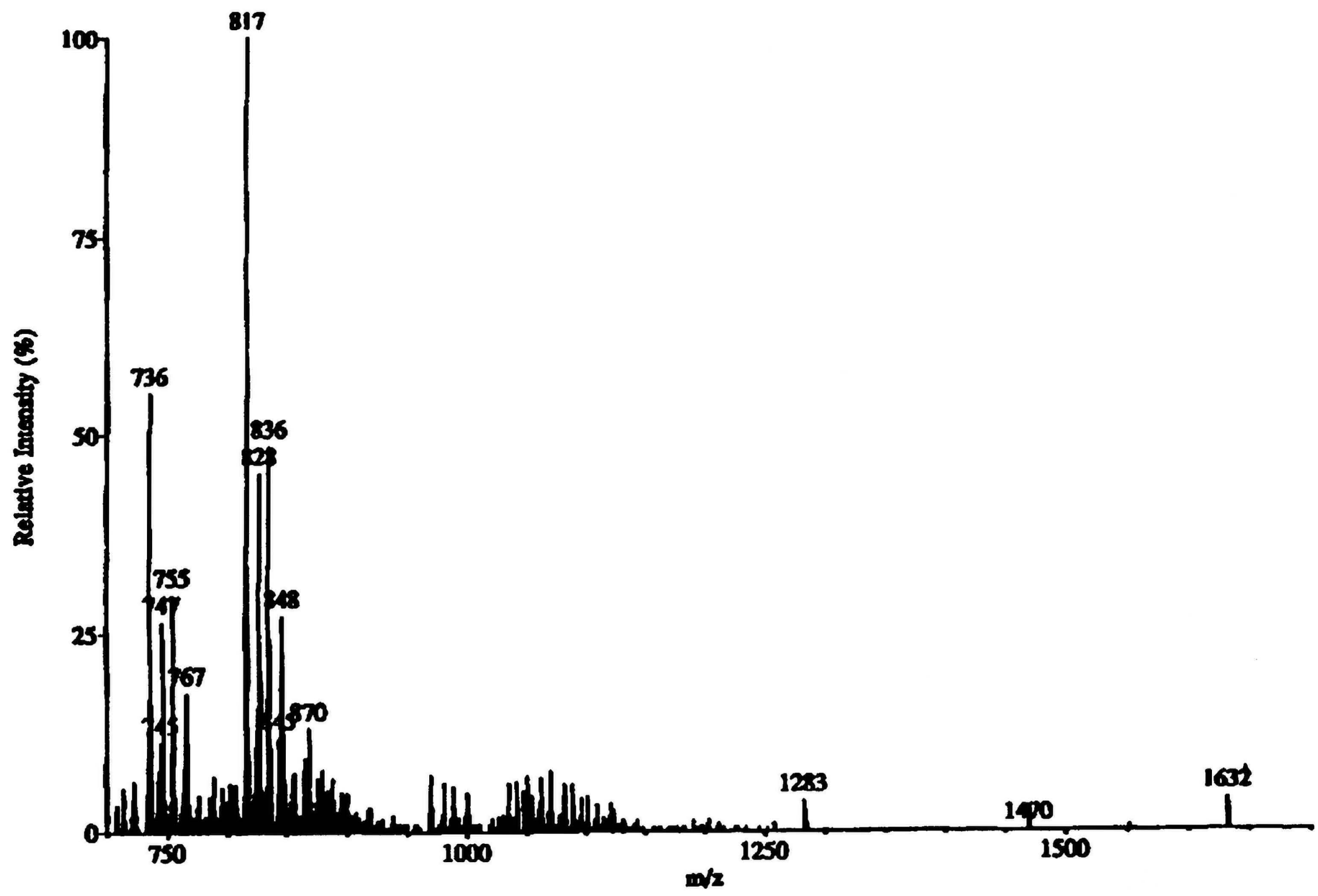

Figure 7. ESMS of the native core oligosaccharide of Aeromonas hydrophila (Chemotype III).

Figure 8. ES CAD MS/MS of the $[\mathrm{M}+2 \mathrm{H}]^{+}$precusor ion $(\mathrm{m} / \mathrm{z} 817)$ of the native core oligosaccharide of Aeromonas hydrophila (Chemotype III).

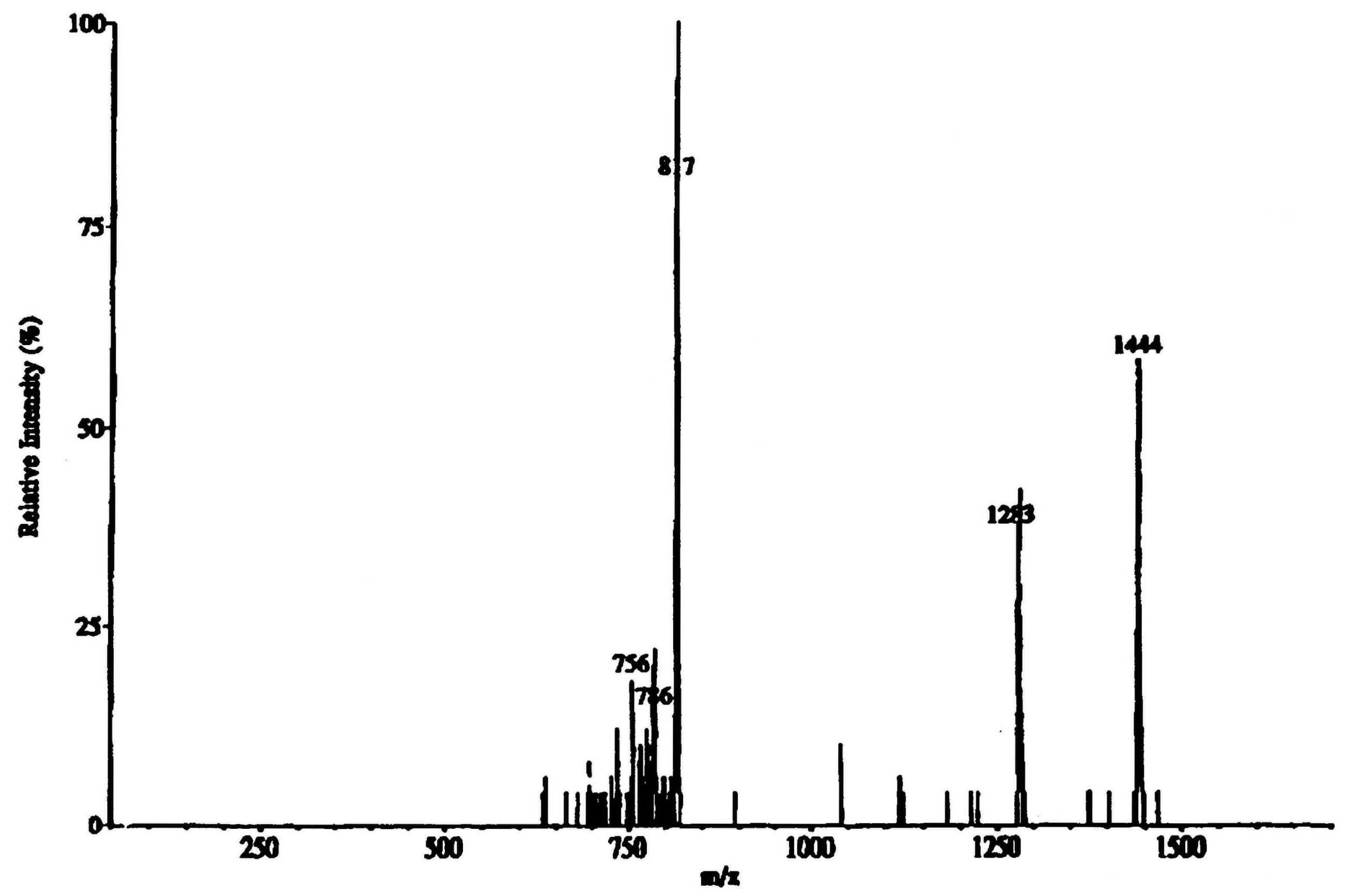




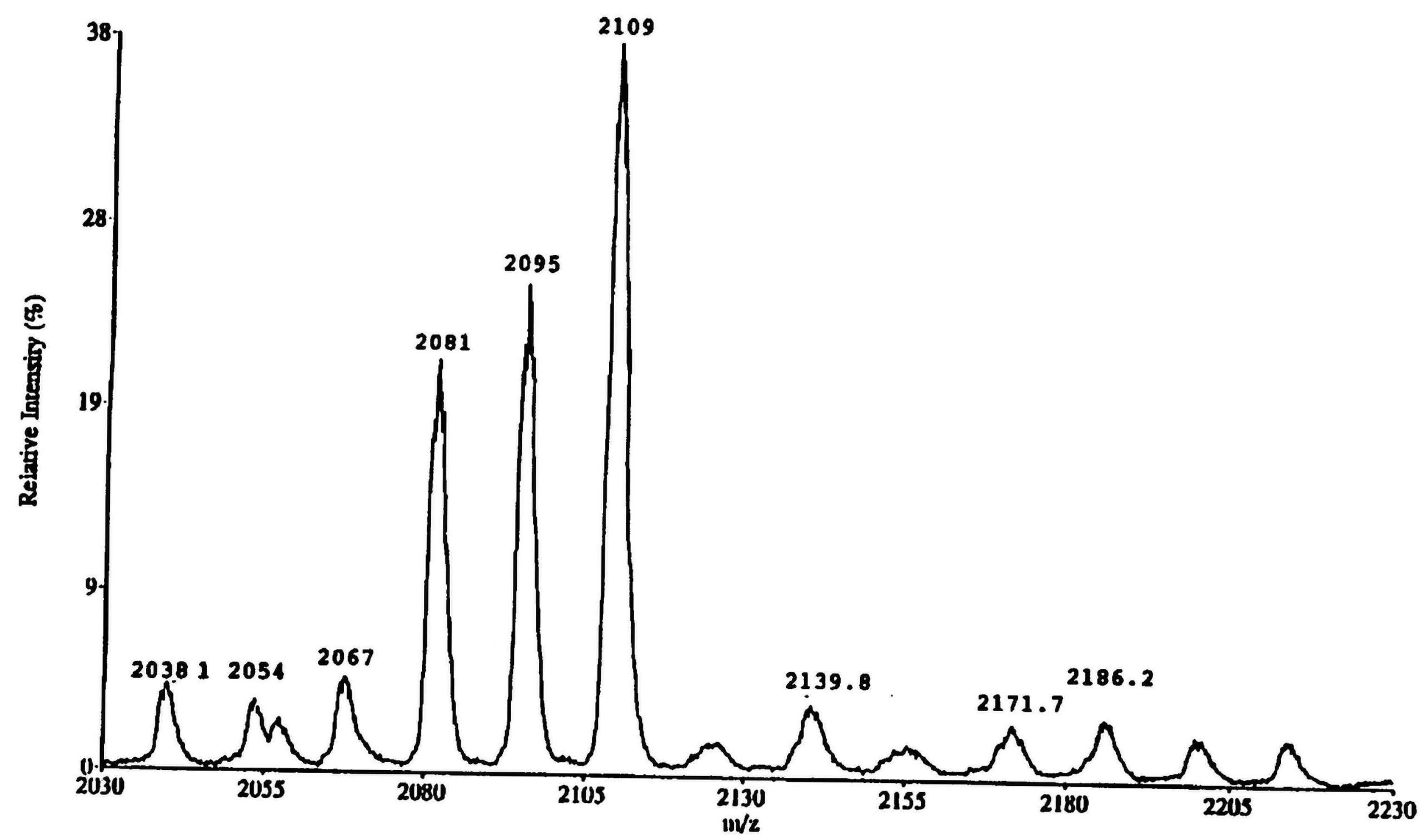

Figure 9. ESMS of the permethylated core oligosaccharide of Aeromonas hydrophila (Chemotype III).

Figure 10. ESMS of the permethylated N-acetylated core oligosaccharide of Aeromonas hydrophila (Chemotype III).

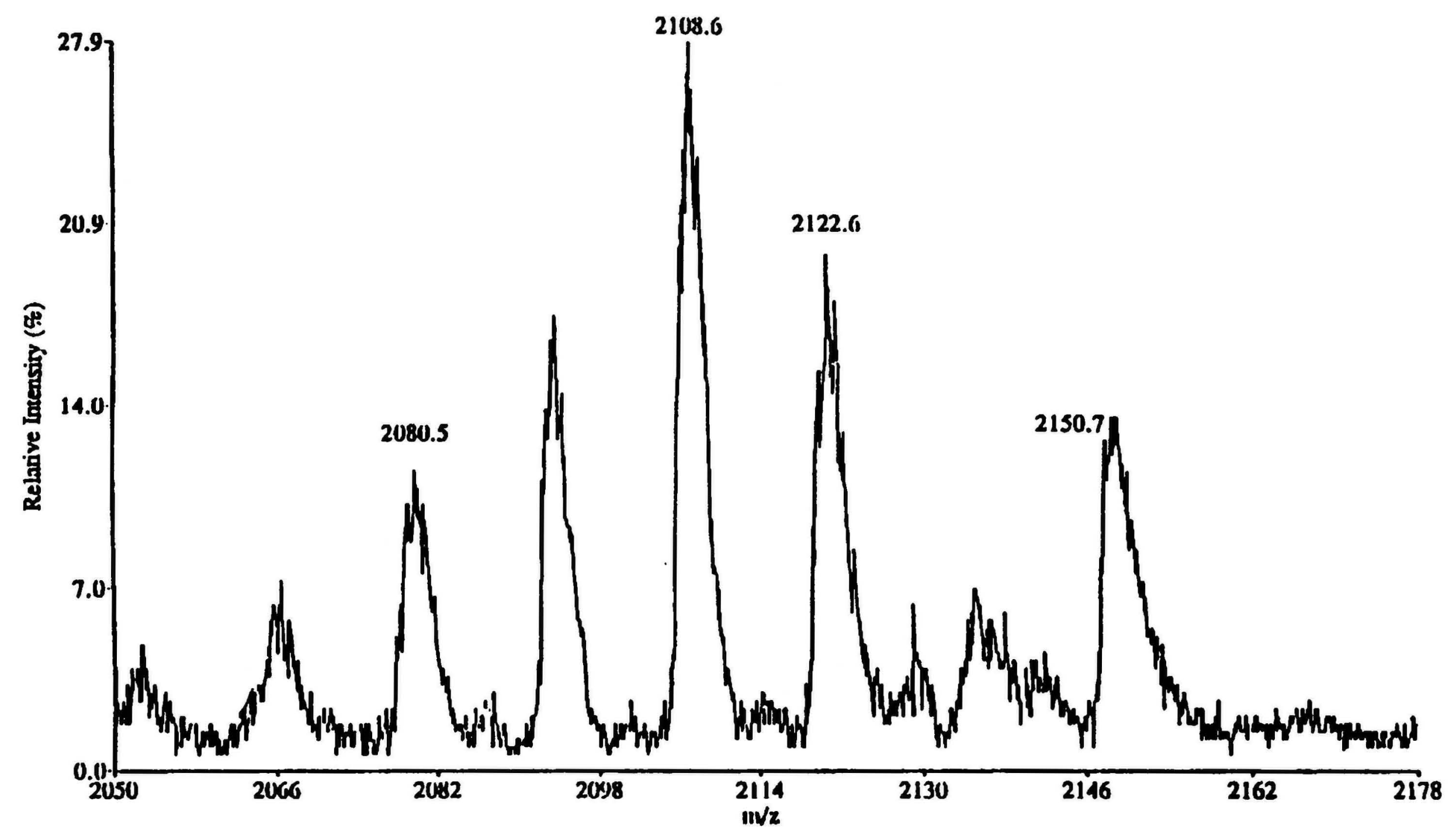


$\mu \mathrm{A}$ of cesium ion current with approximately $35 \mathrm{kV}$ energy. The matrix was either a mixture of glycerol / thioglycerol (1:3) or a mixture of dithioerythritol / dithiothreitol (1:5).

The ESMS (positive ion mode) were measured with a VG-Quattro quadrupolehexapole-quadrupole mass spectrometer,equipped with an electrospray ionization source, capable of analyzing ions up to $\mathrm{m} / \mathrm{z} 4000$. A $486,66 \mathrm{MHz}$ personal computer equipped with Fisons MASSLYNX Mass Spectrometer Data System Software, was used for data acquisition and processing. The temperature of the ES ionization source was maintained at $70^{\circ} \mathrm{C}$. The voltage of the ES capillary was $3.4 \mathrm{KV}$ and the $\mathrm{HV}$ lens was at $0.4 \mathrm{KV}$ throughout the whole operation. ESMS were obtained by scanning in the Multichannel Analysis mode (MCA) with a scan dwell time of 1 second/250 a.m.u.. Spectra are an average of 3-4 scans. The mass scale was calibrated using a polyethylene glycol mixture (PEG 300/600/1000). MS/MS experiments were conducted on the same instrument. Fragment ion spectra of mass-selected ions were induced by collision with argon in the second (RF only) hexapole. Argon collision gas was added in the enclosed chamber of the hexapole to give a pressure of $2 \times 10^{-5} \mathrm{mBar}$ for collisional activation of the sample ions. The resulting fragments were analyzed by the second quadrupole. Collision energies of approximately $50 \mathrm{eV}$ were used in all MS/MS experiments.

\section{Conclusion}

FAB-MS, ESMS and ES CAD MS/MS have assisted in the complete structural characterization and confirmation of the revised molecular sequence of the core oligosaccharide of Aeromonas hydrophila, (Chemotype III) and constitutes an unique approach to the elucidation of more sophisticated natural bacterial polysaccharide structures containing the C-6 substituted furanosidic bicyclic 1,7-lactone form of Kdo. Both FAB-MS and ESMS (in the positive ion modes) showed that after methylation, the reducing terminal furanosidic Kdo unit which is present in a 1,7-lactone (or furanosidic bicyclic 1,7-lactonized Kdo) affords a series of major components for which we have proposed tentative structures. We have postulated that the formation of such structures is the result of the opening of the 1,7-lactone of the reducing terminal bicyclic furanosidic Kdo followed by a series of Cmethylations. It is also apparent that the characteristic molecular ion fingerprint afforded by the four major products allows facile identification of core oligosaccharides containing a C-6 substituted reducing furanosidic Kdo residue prone to forming 1,7-lactone which will escape detection by conventional hydrolytic and colorimetric methods of analysis.

\section{References}

[1] Acuigrup, Bull. Cent. Etud. Rech. Sci. Biarritz, 12 (1979) 493.

[2] W. A. Davis, J. G. Krano and F. Garagusi, Medicine, 3 (1978) 267.

[3] S. Krug, Z. Bienenforsch, 26 (1979) 178.

[4] J. H. Banoub and D. H. Shaw, Carbohydr. Res., 98 (1981) 93.

[5] J. H. Banoub, Y. M. Choy, F. Michon and D. H. Shaw, Carbohydr. Res, 114 (1983) 267.

[6] F. Michon, D. H. Shaw and J. H. Banoub, Eur. J. Biochem., 145 (1984) 107.

[7] D. H. Shaw and H. J. Hodder, Can. J. Microbiol., 24 (1978) 864.

[8] K. Hisatsune, S. Kondo, T. Iguchi, M. Machida, S. Asou, M. Inaguma and F. Yamamoto, Microbiol. Imminol., 26 (1982) 649.

[9] J. H. Banoub, D. H. Shaw and F. Michon, Carbohydr. Res, 123 (1983) 117.

[10] A. Dell, Adv. Carbohydr. Chem. Biochem,45 (1987) 19.

[11] J. B. Fenn, M. Mann, C.K. Meng, S. F. Wong and C. M. Withehouse, Science, 246 (1989) 64.

[12] E. Katzenellenbogen and E. Romonowska, Eur. J. Biochem., 113 (1980) 205. 
[13] R. Chaby and L. Szabo, Eur. J. Biochem., 70 (1976) 115.

[14] J. H. Banoub, F. Michon, D. H. Shaw and R. Roy, Carbohydr. Res, 128 (1984) 203.

[15] J. H. Banoub and H. J. Hodder, Can. J. Biochem. Cell. Biol., 63 (1985) 1199.

[16] D. H. Shaw, M. J. Squires, E. E. Ishiguro and T. J. Trust, Eur. J. Biochem, 161 (1986) 309.

[17] D. H. Shaw, M. J. Hart and O. Luderit, Carbohydr. Res., 231 (1992) 83.

[18] B. Domon and C. E. Costello, Biochemistry, 27 (1988) 1534.

[19] B. Domon and C. E. Costello, Glycoconjugate J., 5 (1988) 397.

[20] C. Chauvin, P. Thibault, D. Plusquellec and J. Banoub, J. Carbohydr. Chem., 12 (1993) 459.

[21] A. Dell, P. Azadi, P. Tiller, J. Thomas-Oates, H. J. Jennings, M. Beurret and F. Michon, Carbohydr. Res, 200 (1990) 59.

[22] K. L. Busch, G. L. Glish and S. A. McLuckey, Mass Spectrometry/Mass Spectrometry : Techniques and Applications of Tandem Mass Spectrometry, VCH, New York, (1988) pp. 333.

[23] V. Wysocki, Mass Spectrometry in Biological Sciences : A tutorial, NATO ASI Series, Series C : Mathematical and Physical Sciences, M. L. Gros Ed, Kluver Academic Publishers, Dordrecht/ Boston/London, 353 (1992) 59. 


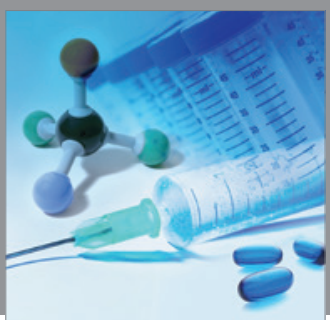

International Journal of

Medicinal Chemistry

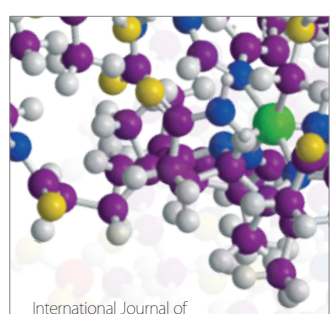

Carbohydrate Chemistry

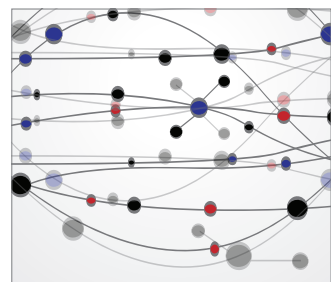

The Scientific World Journal
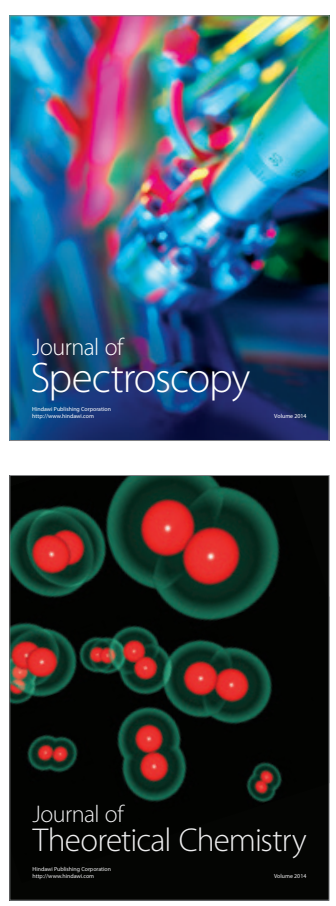
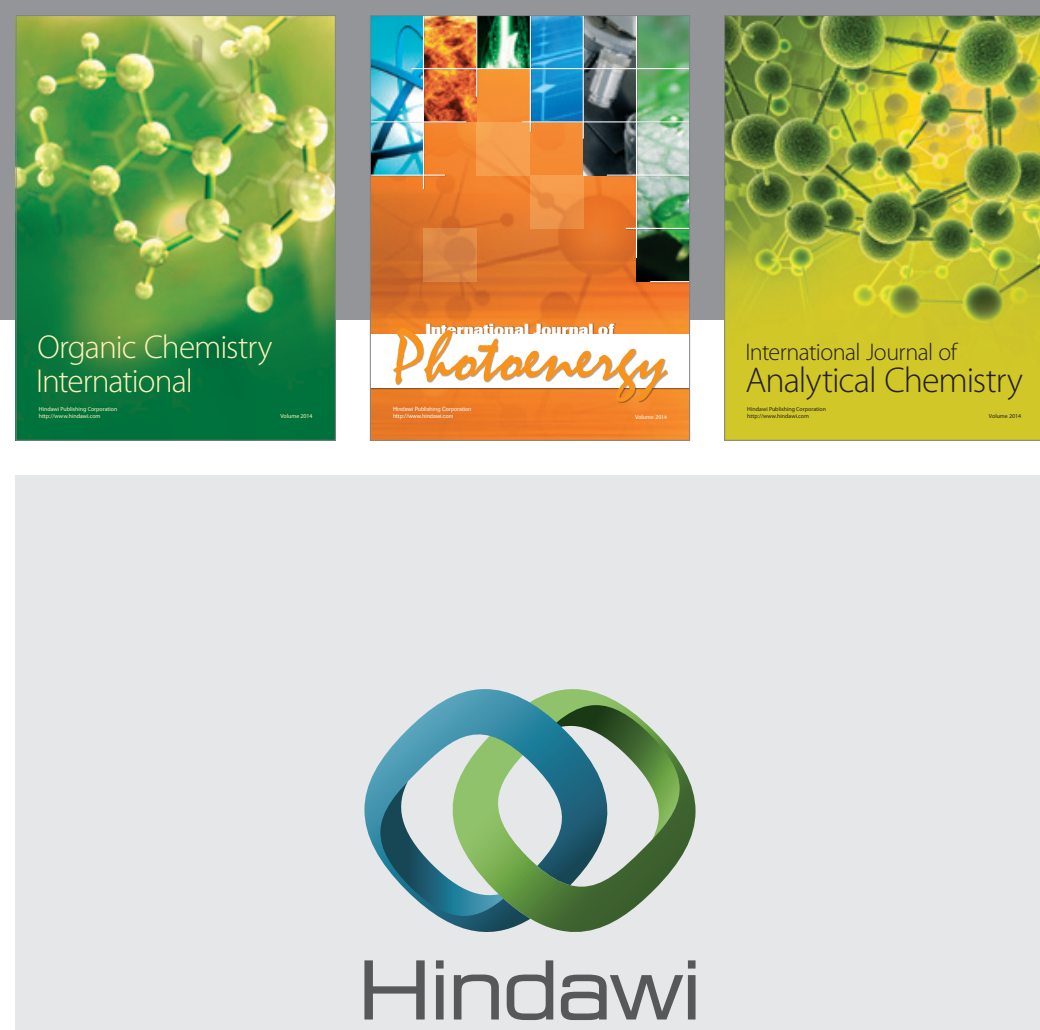

Submit your manuscripts at

http://www.hindawi.com
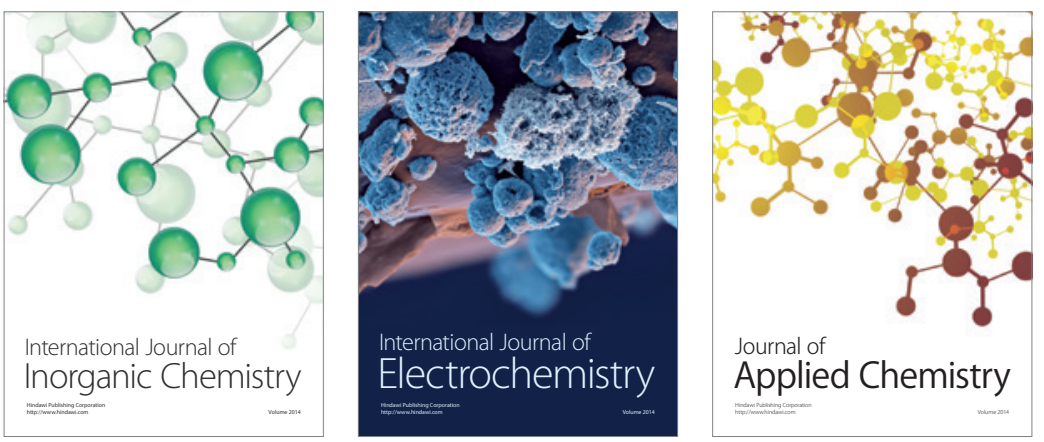

Journal of

Applied Chemistry
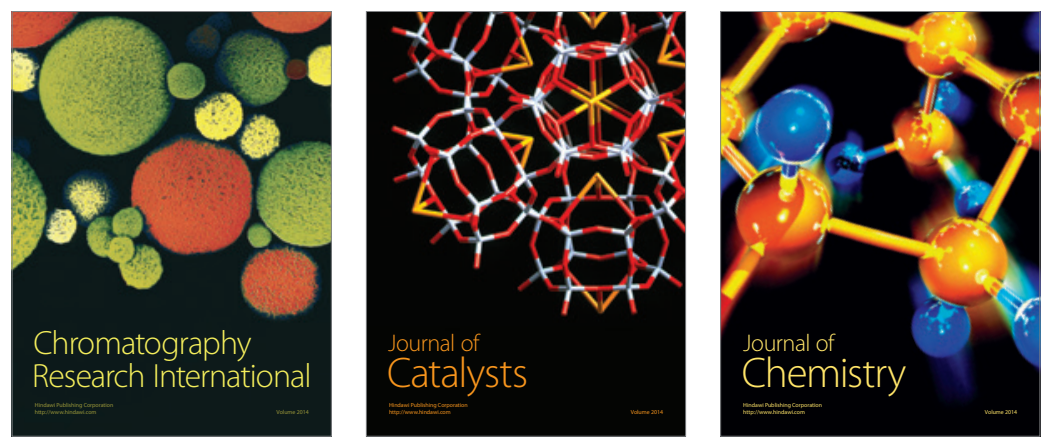
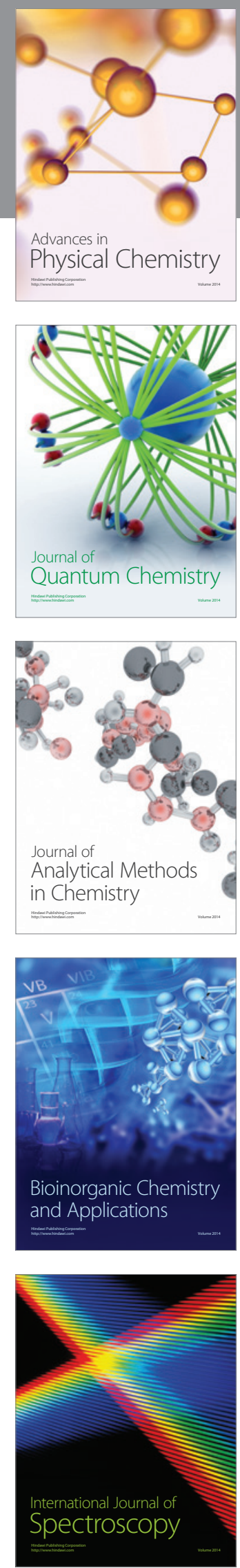